\title{
Erratum to: Break in volition: a virtual reality study in patients with obsessive-compulsive disorder
}

\author{
Pietro Cipresso $\cdot$ Filippo La Paglia • \\ Caterina La Cascia $\cdot$ Giuseppe Riva . \\ Giovanni Albani $\cdot$ Daniele La Barbera
}

Published online: 8 May 2013

(C) Springer-Verlag Berlin Heidelberg 2013

\section{Erratum to: Exp Brain Res}

DOI 10.1007/s00221-013-3471-y

Due to an inadvertent error in typesetting, the names of two authors (Filippo La Paglia and Caterina La Cascia) were mispresented in the address line of this article. This mistake carried over into PubMed and Scopus, where they are erroneously listed as F. L. Paglia and C. L. Cascia). Their names, when using initials, should read as follows:

F. La Paglia · C. La Cascia

The online version of the original article can be found under doi:10.1007/s00221-013-3471-y.

P. Cipresso $(\bowtie) \cdot$ G. Riva

Applied Technology for Neuro-Psychology Lab,

IRCCS Istituto Auxologico Italiano, Via Pellizza da

Volpedo 41, 20149 Milan, Italy

e-mail: p.cipresso@auxologico.it

F. La Paglia · C. La Cascia - D. La Barbera

Department of Experimental Biomedicine and Clinical

Neuroscience - section of Psychiatry, University of Palermo,

Palermo, PA, Italy

G. Riva

Department of Psychology, Catholic University of the Sacred

Heart, Largo Gemelli, 1, 20123 Milan, Italy

G. Albani

Division of Neurology and Neurorehabilitation, San Giuseppe

Hospital, IRCCS Istituto Auxologico Italiano, Piancavallo,

VB, Italy 